\title{
Impulsive Stimulated Light Scattering at High Pressure - Precise Determination of Elastic Constants of Opaque Materials
}

J.C. Crowhurst, J.M. Zaug, E.H. Abramson, J.M. Brown, D.W. Ahre

U.S. Department of Energy

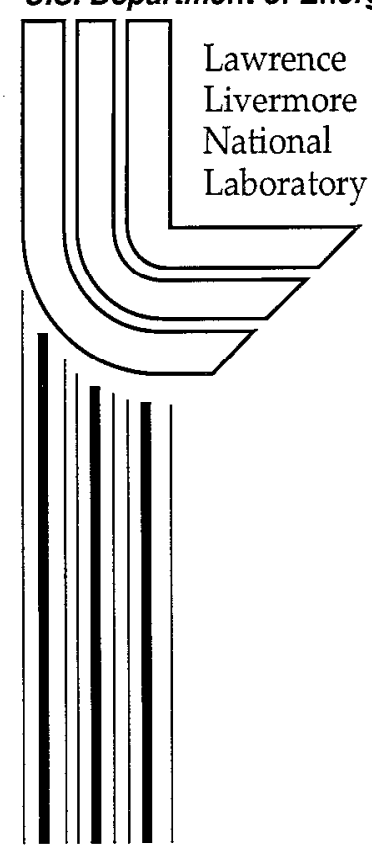

This article was submitted to $40^{\text {th }}$ European High-Pressure Research Group Meeting, Edinburgh, Scotland, September 4-7, 2002

\section{August 22, 2002}




\section{DISCLAIMER}

This document was prepared as an account of work sponsored by an agency of the United States Government. Neither the United States Government nor the University of California nor any of their employees, makes any warranty, express or implied, or assumes any legal liability or responsibility for the accuracy, completeness, or usefulness of any information, apparatus, product, or process disclosed, or represents that its use would not infringe privately owned rights. Reference herein to any specific commercial product, process, or service by trade name, trademark, manufacturer, or otherwise, does not necessarily constitute or imply its endorsement, recommendation, or favoring by the United States Government or the University of California. The views and opinions of authors expressed herein do not necessarily state or reflect those of the United States Government or the University of California, and shall not be used for advertising or product endorsement purposes.

This is a preprint of a paper intended for publication in a journal or proceedings. Since changes may be made before publication, this preprint is made available with the understanding that it will not be cited or reproduced without the permission of the author.

This report has been reproduced directly from the best available copy.

Available electronically at http://www.doc.gov/bridge

Available for a processing fee to U.S. Department of Energy

And its contractors in paper from

U.S. Department of Energy

Office of Scientific and Technical Information

P.O. Box 62

Oak Ridge, TN 37831-0062

Telephone: (865) 576-8401

Facsimile: (865) 576-5728

E-mail: reports@adonis.osti.gov

Available for the sale to the public from

U.S. Department of Commerce

National Technical Information Service

5285 Port Royal Road

Springfield, VA 22161

Telephone: (800) 553-6847

Facsimile: (703) 605-6900

E-mail: orders@ntis.fedworld.gov

Online ordering: http://www.ntis.gov/ordering.htm

OR

Lawrence Livermore National Laboratory

Technical Information Department's Digital Library

http://www.llnl.gov/tid/Library.html 


\title{
IMPULSIVE STIMULATED LIGHT SCATTERING AT HIGH PRESSURE - PRECISE DETERMINATION OF ELASTIC CONSTANTS OF OPAQUE MATERIALS
}

\author{
J. C. Crowhurst ${ }^{\mathrm{a}^{*}}$, J. M. Zaug ${ }^{\mathrm{a}}$, E. H. Abramson ${ }^{\mathrm{b}}$, J. M. Brown ${ }^{\mathrm{c}}$, and D. W. \\ Ahre $^{a}$ \\ ${ }^{a}$ Lawrence Livermore National Laboratory, Livermore 9455I, USA \\ ${ }^{\mathrm{b}}$ Department of Chemistry, University of Washington, Seattle 98195, USA \\ ${ }^{c}$ Department of Earth and Space Sciences, University of Washington, Seattle 98195 , \\ USA
}

Impulsive stimulated light scattering has been used to measure interfacial wave propagation speeds and elastic constants under conditions of high pressure. Data obtained from single-crystal $\mathrm{Ge}$ and $\mathrm{Fe}$, and from polycrystalline $\mathrm{Ta}$ is presented. The method is complementary to other techniques for obtaining this type of information. There appears no fundamental reason why it cannot be extended to the I Mbar regime.

Impulsive stimulated light scattering (ISLS) is the name given to one of several experimental techniques in which light is used to both produce and investigate the behaviour of dynamic material gratings. Depending on the time scale of the experiment and the dominant interaction, the excited gratings may be acoustical or thermal in nature, (amongst other types), or combinations thereof. To obtain the data reported here the gratings were obtained by combining in the sample two laser pulses at a known angle of convergence. The diffracted intensity as a function of time after this event, of a frequencydoubled probe pulse was then recorded. The pulses used to generate and investigate the gratings were of a duration of $\sim 100 \mathrm{ps}$, and had the frequencies of the first and second Nd:YAG harmonics, respectively. In general, other combinations of frequencies and pulse widths may be used, depending on the application. See for example, Crimmins et al [1], and references therein.

A recorded time series is presented in Figure 1. A strongly modulated signal, made up of several frequencies, is evident. The modulation is due to interference between acoustic waves, and between the waves and a static thermal grating. The presence of the acoustic waves is a result of the combination of the elasticity of the medium, and a spatially periodic variation in density, which is in turn created by thermal expansion due to absorption of the incident exciting light.

ISLS has been used several times to measure elastic constants and thermal transport properties of various materials under conditions of high pressure in the diamond anvil cell [2]. The technique is appropriate to the high-pressure regime since it does not require mechanical contact with the sample and may also be applied to specimens of nearmicroscopic dimensions. Furthermore, the apparatus of ISLS is "bench-top" sized and relatively inexpensive. It shares these advantages with Brillouin scattering, for example, but is also inherently more precise than the latter technique. When applied to opaque materials, ISLS has a further advantage over Brillouin scattering, which is that the signal strength is large, and spectra may be acquired in minutes or seconds. By comparison, a Brillouin spectrum may take hours to collect [3].

*E-mail: crowhurst1@1lnl.gov 
The high-pressure data presented here was all obtained using the ISLS system of the University of Washington. However, a new system has recently been completed at LLNL, which, while conceptually identical, offers some practical advantages. These advantages may be traced to the more powerful laser used in the newer system. This device eliminates the need for Pockels cells to select the required pulses from a mode-locked Q-switched envelope. Instead, the regenerative amplifier device used in the LLNL system (a TimeBandwidth Jaguar) emits a single near-IR pulse that is sufficiently energetic to be split into two before being recombined in the sample. The geometrical arrangement used guarantees temporal coincidence. Shortly after the near-IR pulse $(\sim 6 \mathrm{~ns})$ the laser also emits a green pulse from a separate aperture. Overall, the system requires shorter beam paths and fewer optics, both of which lead to long-term stability. The newer laser also has a high repetition rate, which is a little under $4 \mathrm{kHz}$. The result is that shot-to-shot averaging time is significantly reduced. It is noted that the pulse width of the laser may easily be adjusted by inserting the appropriate etalon. The LLNL system has the option of 50, 100, or 200 ps pulse widths.

In the context of the anvil cell, it is more difficult to apply ISLS or Brillouin scattering to opaque materials than to transparent materials. The former application is necessarily complicated by the fact that it involves a material interface, formed by the opaque sample in contact with a contiguous material, which is typically the pressure medium. The acoustic behaviour of this interface is dependent on the clastic properties of both components. To model the behaviour the computational procedure developed by Every et al [4] has been employed, which evaluates the appropriate component of the relevant elastodynamic Green's function. The procedure is general and may be applied to any combination of crystal symmetry and orientation, as well as to more complicated situations, such as the three-component system studied by Crowhurst et al [3].

Examples of high pressure ISLS data obtained from opaque samples are presented in Figs 2-4

The aim of ongoing research is to extend ISLS measurements on metals to pressures of up to 1 Mbar, with emphasis on iron, as well as on metals of programmatic interest to LLNL.

\section{Acknowledgements}

This work was performed under the auspices of the U. S. Department of Energy by the University of California, Lawrence Livermore National Laboratory under Contract No. W7405-Eng-48.

\section{References}

[1] Crimmins, F. T., Maznev, A. A. and Nelson, K. A., Appl. Phys. Lett. 74, 1344 (1999).

[2] Abramson, E. H., Brown, J. M. and Slutsky, L. J., Annu. Rev. Phys. Chem. 50, 279 (1999).

[3] Crowhurst, J. C., Hearne, G. R., Comins, J. D., Every, A. G., and Stoddart, P. R., Phys. Rev. B 60 , RI4 990 (1999).

[4] Every, A. G. and Briggs, G. A. D., Phys. Rev. B 58, 1601 (1998).

[5] Crowhurst, J. C., Abramson, E. H., Slutsky, L. J., Brown, J. M., Zaug, J. M. and M. D. Harrell, Phys. Rev. B, 64, 100103 (2001).

[6] Katahara, K. W., Manghnani, M. H. and Fisher, E. S., J. Appl. Phys, 47, 434 (1976).

[7] Cynn, H. and Yoo, C-S., Phys. Rev. B 59,8526 (1999). 
FIGURE CAPTIONS:

FIGURE 1 Time series obtained at LLNL for propagation on (100) Ge along the [001] direction, (a), and (b), the corresponding frequencies. The two intense peaks located at approx. 1 and $2 \mathrm{GHz}$ correspond to the Rayleigh wave moving with respect to the static thermal background, and two Rayleigh waves counter-propagating, respectively. The inset shows peaks of smaller intensity. The peak located at approx. $1.7 \mathrm{GHz}$ has the directional dependence of the quasilongitudinal wave of $\mathrm{Ge}$. Some of the other peaks in the spectrum are due to this wave propagating in the same, and in the opposite direction, to the Rayleigh wave.

FIGURE 2 Dependence on direction of propagation of the velocities of the surface waves of (100) $\mathrm{Ge}$ (a) in air at atmospheric pressure, and, (b) - (d), in methanol at the indicated applied pressures. At ambient pressure the measured velocities are those of the Rayleigh wave and pseudo-surface acoustic wave. The solid and dashed lines represent the results of the one-component Green's function calculation of the velocities of the RW and pSAW, respectively. In contact with methanol, the measured mode is a Scholte wave; the lines represent the results of the two-component calculation. As evidenced by the growing anisotropy, the dependence on the acoustic parameters of the solid increases with increasing pressure. At $2.2 \mathrm{GPa}$ the pseudo-surface and Rayleigh type waves are sufficiently separated in velocity to be resolvable as distinct branches.

This is a reproduction of Fig. 2 of Crowhurst et al [5].

FIGURE 3 Dependence on direction of propagation of the velocities of the surface waves of (100) $\mathrm{Fe}$ in an Ar pressure medium at $8 \mathrm{GPa}$. The dashed lines are the calculated velocities made on the basis of elastic constants extrapolated from literature values of lowpressure pressure derivatives. The best fit to the data was obtained with $\sim 5 \%$ reduction in the $\mathrm{Fe} c_{44}$ value.

FIGURE 4 Elastic constants of polycrystalline Ta measured to a pressure $30 \mathrm{GPa}$ in an $\mathrm{Ar}$ medium. The dashed lines represent the extrapolation of literature values [6]. The pressure reached in the latter work is indicated by the vertical line. To obtain both elastic constants literature values of the bulk modulus of $\mathrm{Ta}$ [7] were used when performing the Green's function calculation. 

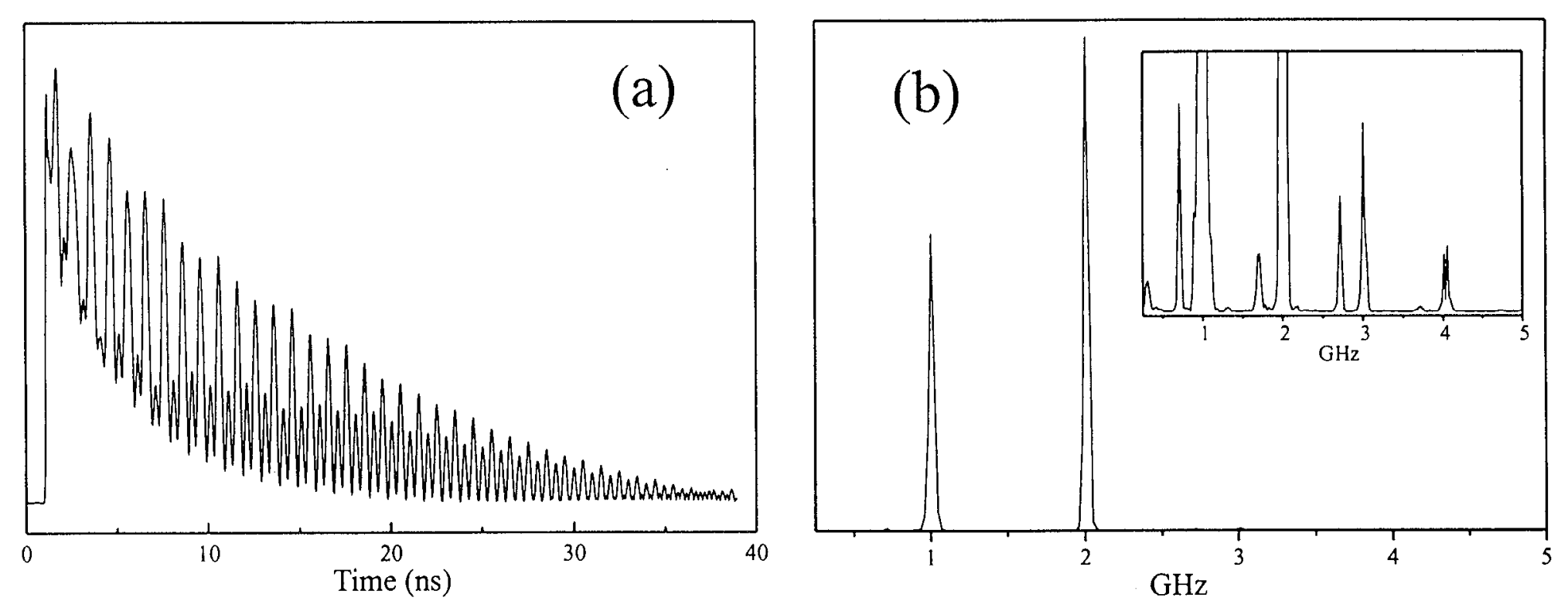


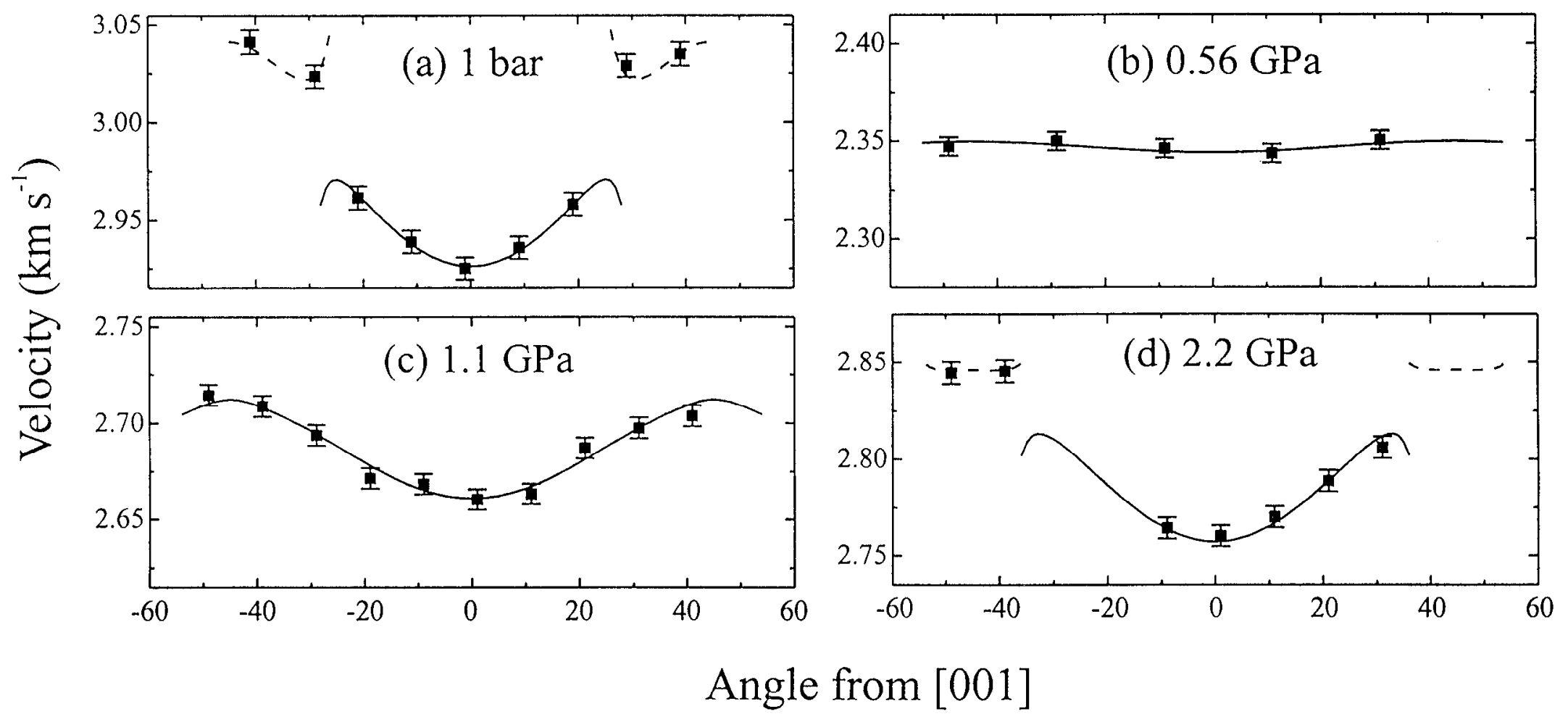




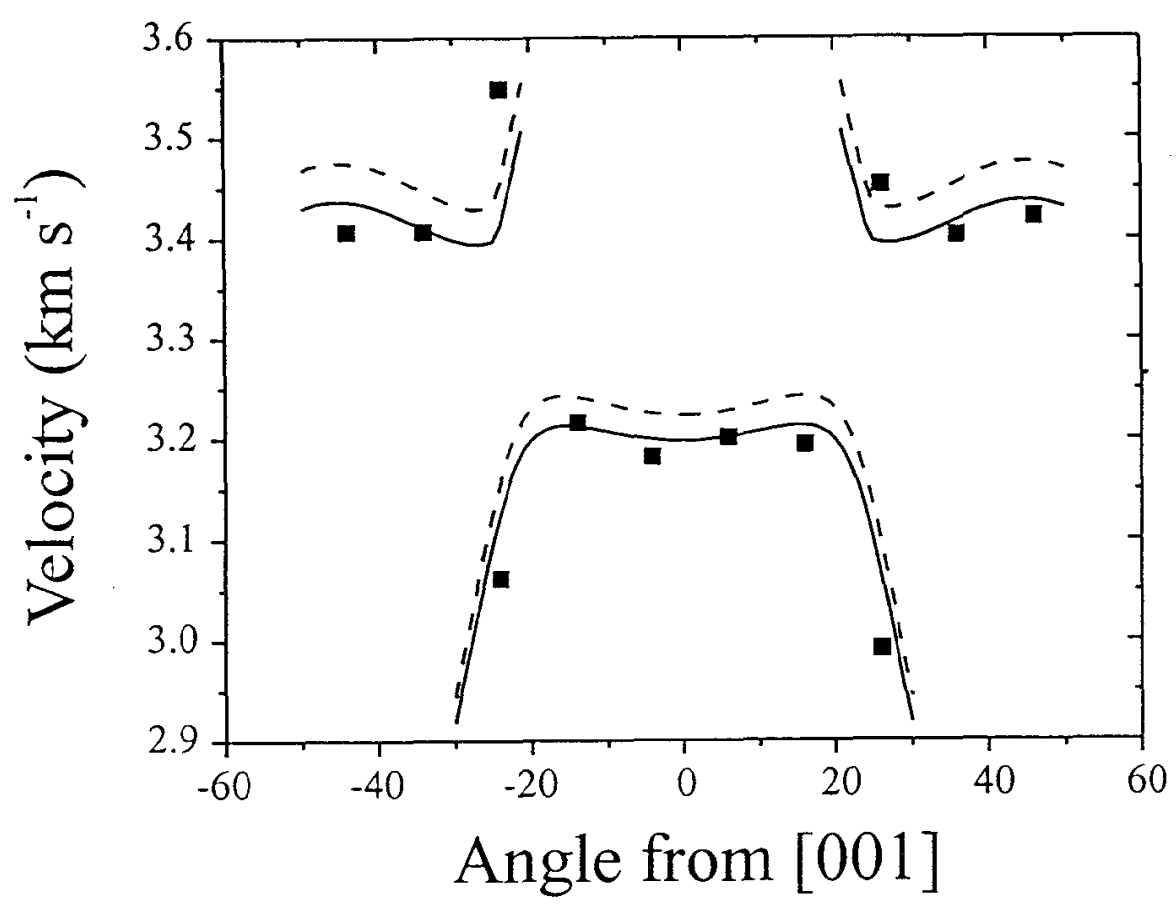




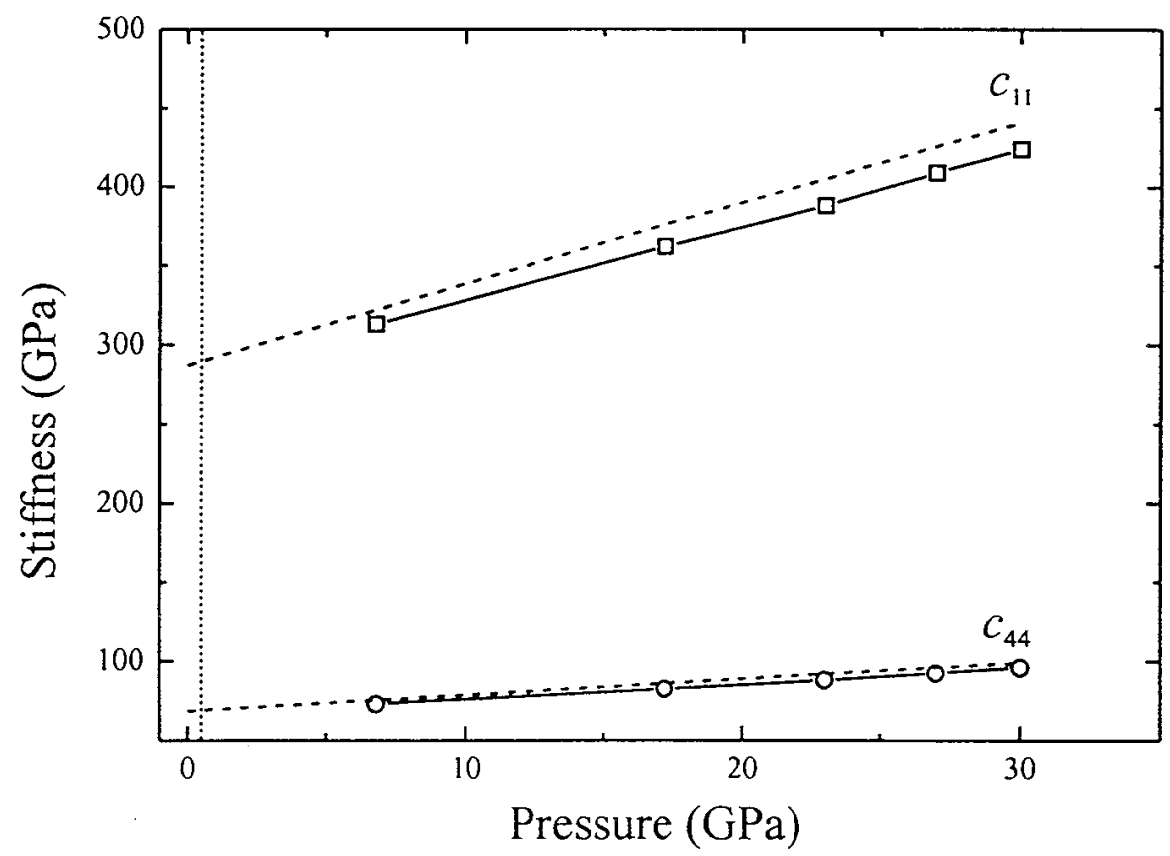

